\title{
O Que Há de Errado com o Igualitarismo de Fortuna?*
}

\author{
Lucas Petroni \\ Doutor em Ciência Política pela Universidade de São Paulo (USP). Pesquisador de pós-doutorado (2019-2020) \\ no Departamento de Filosofia da Universidade de Yale. New Haven, Connecticut, EUA. \\ E-mail: lucas.petroni@gmail.com. ORCID: https://orcid.org/0000-0001-9299-4767
}

\section{INTRODUÇÃO}

\begin{abstract}
A s teorias igualitárias da justiça podem ser organizadas com base em duas disputas teóricas fundamentais": (I) o problema da "igualdade de quê?", isto é, qual a melhor métrica distributiva para uma dada teoria da justiça; e (II) o problema da "exploração interpessoal", como tornar princípios distributivos (mais) sensíveis às nossas escolhas individuais. Em uma formulação sucinta, o objeto de disputa na controvérsia (I) é determinar qual a métrica distributiva mais apropriada, ou qual o melhor equalisandum, para uma teoria da justiça (cf. Sen, 1979, 1992; Dworkin, 1981a, 1981b; Cohen, 1993). Nesse tipo de debate, queremos saber em quais aspectos as pessoas devem ser equalizadas do ponto de vista da justiça, e quais tipos de bens sociais devem ser distribuídos entre as pessoas. Já a controvérsia (II) diz respeito a outro tipo de problema teórico, a saber, a necessidade de especificarmos os parâmetros de acordo com os quais esses bens devem ser distribuídos. Um típico problema de pesquisa aqui é encontrar princípios distributivos que sejam "à prova de exploração" entre as pessoas para as quais esses princípios são
\end{abstract}

* Os argumentos apresentados neste artigo circularam em diferentes
formatos e ocasiões ao longo dos últimos anos. Gostaria de registrar
meu agradecimento aos comentários e sugestões de Mathias Alencastro,
Nunzio Ali, Thomas Bustamante, Bruno Camilloto, Filipe Campello, Darlei
Dall'Agnoll, Renato Francisquini, Nicole Gayard, Tiago Hyra, Raquel Kritsch,
Elisa Klüger, Gabriela Martínez, Rúrion Melo, Humberto Meza, Alessandro
Pinzani, Luiz Repa, Ivan Rodrigues, Leonardo Rosa, Jorge Sell, Maria
Hermínia Tavares de Almeida, Raissa Wihby Ventura, Álvaro de Vita, Thadeu
Weber e a um(a) parecerista anônimo(a). Agradeço à Fundo de Amparo à
Pesquisa do Estado de São Paulo (Fapesp) e ao Centro Brasileiro de Análise
e Planejamento (Cebrap) pelo apoio institucional fornecido a esta pesquisa.

DADOS, Rio de Janeiro, vol.63(2): e20180094, 2020.

http://dx.doi.org/10.1590/001152582020208 
concebidos (Wolff, 1998, 2007). Os esforços mobilizados no problema (II) são menos centrados na busca pelo equalisandum correto das teorias da justiça, e mais interessados na procura por parâmetros capazes de avaliar a legitimidade de reivindicações distributivas. Procura-se distinguir, por exemplo, as reivindicações de pessoas deliberadamente subprodutivas, das reivindicações de pessoas involuntariamente pouco produtivas.

Nenhuma concepção de justiça levou tão a sério esses dois problemas como as teorias que constituem o chamado igualitarismo de fortuna ${ }^{2}$. De acordo com essa corrente teórica, o ideal normativo que deveria orientar o igualitarismo é a necessidade de retificar e, no limite, neutralizar os efeitos distributivos de circunstâncias involuntárias sobre a vida das pessoas. Isto significa neutralizar os efeitos distributivos da má sorte, ou da fortuna pessoal por meio de mecanismos distributivos (Dworkin, 1981a, 1981b; Arneson, 1989, 2002; Cohen, 1989, 1993) ${ }^{3}$. Para essas teorias, o valor da equidade distributiva é fundamental: uma distribuição é justa quando não reflete desvantagens moralmente arbitrárias entre as pessoas. Os igualitários de fortuna acreditam que para realizar esse objetivo precisamos, em primeiro lugar, oferecer uma resposta teoricamente convincente para os dois problemas apresentados acima. Ou seja, indicar qual é a métrica distributiva mais adequada para uma teoria da justiça, e de que forma podemos evitar instâncias de exploração interpessoal. Nesse sentido, a atual configuração da agenda de pesquisa sobre a justiça pode ser explicada, em grande medida, pelo sucesso que o igualitarismo de fortuna obteve na filosofia política contemporânea e, no interior do campo igualitário. Uma das razões para esse sucesso é sua capacidade de oferecer simultaneamente uma concepção teoricamente rigorosa e politicamente radical de justiça distributiva.

A despeito da importância do igualitarismo de fortuna e dos debates engendrados por ele, meu objetivo neste artigo é argumentar que essa maneira de compreender a agenda de pesquisa igualitária possui graves limitações. Mais especificamente, gostaria de mostrar que, ao não considerar outras categorias fundamentais do ideal igualitário, como a noção de respeito mútuo, o igualitarismo de fortuna, pelo menos em sua forma atual, corre o risco de transformar o projeto igualitário em um empreendimento conceitualmente incompleto e teoricamente desestimulante. Concebido apenas como um problema de equidade distributiva, o valor da igualdade representa um entrave conceitual para as aspirações do igualitarismo contemporâneo. 
Na segunda e na terceira seção apresento a estrutura conceitual do igualitarismo de fortuna reconstruindo suas duas formulações mais influentes: a igualdade de oportunidades para recursos sociais, proposta por Ronald Dworkin (1981a, 1981b, 2005), e a igualdade de oportunidade para bem-estar, defendida por Richard Arneson $(1989,2002)$. Em seguida, apresento nas seções quatro e cinco duas críticas diferentes às teorias fortunistas. Por falta de melhor nomenclatura, chamarei a primeira delas de crítica conceitual, na medida em que explora a plausibilidade ou não da separação (conceitual) entre escolha e circunstância. A segunda crítica, que denominarei de crítica igualitária, tem como foco o próprio fundamento normativo do igualitarismo de fortuna. De acordo com a crítica igualitária, o erro do igualitarismo de fortuna não reside tanto em um problema conceitual (muito menos ideológico), mas sim em uma interpretação empobrecedora do valor moral da igualdade. Interpretação essa que, seguindo parte do debate mais recente sobre o tema, denominarei de visão distributiva da igualdade (cf. Scheffler, 2015). De acordo com esse modo de interpretar o valor da igualdade, duas pessoas são iguais quando um determinado padrão distributivo as trata de modo equitativo ${ }^{4}$. Gostaria de mostrar por que a crítica igualitária (mas não necessariamente a crítica conceitual), nos obriga a alterar a ordem de prioridade de uma agenda de pesquisa sobre justiça e igualdade na teoria política. Visões não distributivistas do valor da igualdade endereçam às teorias da justiça uma pergunta anterior ao problema da métrica (I) e ao problema da exploração interpessoal (II). Importa saber não apenas o que queremos distribuir, ou quanto alguém está autorizado a reivindicar, mas também como os sujeitos da justiça devem ser tratados; isto é, como devemos conceber nossas relações normativas enquanto reciprocamente responsáveis pela criação de uma sociedade justa. Finalmente, a sexta e última seção ilustra a irredutibilidade dessas duas formas de interpretar a igualdade tomando como objeto o papel da responsabilidade pessoal nas teorias da justiça.

\section{EXPLORAÇÃO INTERPESSOAL E IGUALDADE DE OPORTUNIDADE}

O igualitarismo de fortuna sustenta que uma sociedade justa deve ter por princípio fundamental a neutralização da fortuna e do acaso no acesso a bens distributivos. Nenhuma pessoa deveria ser distributivamente penalizada por causa de circunstâncias involuntárias vividas, como a distribuição natural de habilidades e talentos, ou o acesso privilegiado a recursos econômicos, simbólicos, sociais, usualmente 
adquiridos por herança ou socialização. Nesse sentido, desigualdades só poderiam ser justificadas se, e apenas se, a causa do acesso diferencial a recursos possa ser rastreada inequivocamente às escolhas voluntárias de um indivíduo.

Gostaria de começar esta seção chamando atenção para o papel que cada uma das controvérsias desempenha na estrutura do igualitarismo de fortuna. As principais alternativas em disputa no debate (I) oscilam entre três classes de métricas distributivas: as métricas objetivas, como os bens primários da cooperação social, tal como proposto pela teoria da justiça de John Rawls, as métricas de tipo subjetivo, como as funções de utilidade individual encontrada nas teorias utilitaristas; e as métricas "mistas", nas quais são levados em consideração critérios objetivos e subjetivos simultaneamente ${ }^{5}$. A escolha entre equalizar um grupo de pessoas em relação aos recursos materiais existentes; às preferências subjetivas de cada indivíduo; ou promover indicadores objetivos de qualidade de vida (que podem estar atrelados a uma concepção particular de florescimento humano), podem possuir consequências distributivas radicalmente diferentes. Notemos, contudo, que a decisão de escolher entre diferentes métricas distributivas é crucial para qualquer concepção de justiça, seja ela igualitária ou não. Essa é uma decisão que depende de escolhas de natureza ética e epistemológica feitas por uma teoria, como, por exemplo, se é possível fazer comparações interpessoais de utilidade. Particularmente importante é a concepção de valor, ou "teoria do bem", endossada por uma determinada teoria, i.e., quais são os fatores intrinsecamente valiosos para uma vida humana digna. Isso significa que, em um sentido estritamente metodológico, responder à pergunta (I) é, de fato, um problema importante para o igualitarismo. Porém, esse é também um tipo de problema metodologicamente trivial, na medida em que ele precisa ser enfrentado por qualquer argumento sobre distribuições justas. O debate sobre qual métrica devemos adotar na avaliação de distribuições justas é redutível ao debate, mais geral, sobre quais fatores constituem uma argumentação normativa sobre a justiça. Ou seja, quais são as categorias defendidas por uma teoria que constituem os critérios de avaliação moral relevantes para uma vida considerada boa ${ }^{6}$.

Uma consequência dessa trivialidade é o fato de ser perfeitamente possível resolver o problema da métrica com base em argumentos ortogonais aos problemas específicos do ideal igualitário. A teoria da justiça igualitária de Rawls (1997) é um bom exemplo disso. De acordo 
com o já conhecido argumento rawlsiano, concepções utilitaristas de justiça - e que, portanto, adotam uma métrica subjetiva - não seriam capazes de "levar a sério a distinção entre as pessoas" (1997:33). Rawls argumenta que o princípio de maximização das preferências individuais incorre em um tipo grave de desrespeito em relação aos valores e planos de vida pessoais quando ele se torna o critério de distribuição social. Isso porque a maximização de bem-estar agregado autoriza o tratamento instrumental do plano de vida de alguns membros em detrimento do plano de outros. Teorias utilitaristas da justiça justificam a desconsideração da felicidade das pessoas que contribuem pouco para o bem-estar coletivo em nome das expectativas de vida tidas como mais "eficientes" no cômputo geral da utilidade social. Contra essa consequência moralmente inaceitável das teorias utilitaristas, Rawls argumenta pelo valor incondicional de cada plano de vida existente em uma sociedade, procurando mostrar que a sua concepção de justiça possui a vantagem de nos eximir do "risco de ter de concordar com uma perda de liberdade no decorrer da vida para que outros gozem de um bem maior" (1997:216). O valor intrínseco da autonomia é a principal razão pela qual Rawls endossa uma métrica estritamente objetiva para a distribuição: um conjunto de bens primários socialmente relevantes para qualquer plano de vida pessoal que venha a ser adotado voluntariamente pelos membros da cooperação social (1997:108-113).

Não é o meu objetivo neste artigo disputar a validade das interpretações éticas presentes nas teorias igualitárias. Quero apenas ilustrar o argumento segundo o qual o assim chamado debate "igualdade de quê?" não é um problema metodológico exclusivo das teorias igualitárias, já que pode ser reduzido ao problema de determinar os fatores normativamente relevantes de uma dada concepção de justiça.

Isso nos leva ao segundo problema, referente à exploração interpessoal. Por que, afinal, a exploração interpessoal seria tão problemática para concepções igualitárias? Teóricos e teóricas anti-igualitárias alegam que o igualitarismo tende a priorizar a distribuição coletiva de recursos vis-à-vis o valor que esses mesmos recursos possuem para cada indivíduo; i. e., como cada pessoa valoriza e adquiriu seu quinhão de riqueza. Hayek (1960) e Nozick (1974) argumentam que a primazia da distribuição coletiva sobre a produção individual tem como consequência a exploração interpessoal dos verdadeiros produtores e produtoras da riqueza social, pelos sujeitos beneficiados pelos arranjos distributivos ${ }^{7}$. O rationale dessa crítica é simples: da perspectiva dos produtores, toda 
forma de distribuição representa também uma forma de extração, e a obsessão igualitária com resultados distributivos predeterminados ignora que a extração de recursos - ou do tempo de trabalho - de uma pessoa, não é isenta de consequências normativas. Para a crítica libertariana ao igualitarismo, tratar as pessoas como iguais significa tratá-las como livres para decidirem sua própria contribuição produtiva para a sociedade, assumindo responsabilidade pelas consequências distributivas dessas escolhas. Digamos que algumas pessoas optem voluntariamente por não contribuir para a riqueza social. Digamos ainda que, a despeito de seus potenciais produtivos, algumas pessoas optem, por exemplo, por dedicar seu tempo a atividades que não sejam socialmente valiosas em nenhum sentido - não apenas por não estarem atreladas à remuneração do trabalho, mas também porque não tomam parte em atividades de cuidado ou de produção cultural não remuneradas. Para a crítica libertariana, impor uma igualdade estrita de recursos entre pessoas com disposições diferentes de participação na produção social implica enviesar o ônus da cooperação contra os indivíduos mais produtivos e a favor dos preguiçosos. Como afirma Nozick, "a tributação da remuneração do trabalho é equiparável [on par with] ao trabalho forçado" (1974:169) ${ }^{8}$.

Não precisamos ir tão longe assim para reconhecer que a exploração interpessoal pode ser uma fonte de problema para teorias igualitárias. Uma interpretação simplista da igualdade pode promover relações de exploração entre pessoas com disposições de produção diferentes para a riqueza social. Esse é justamente o argumento do igualitarismo de fortuna contra formas tradicionais de igualitarismo. De modo geral, qualquer teoria igualitária moderna toma como ponto de partida a premissa de que certas formas de desigualdade material socialmente reconhecidas são injustas. Uma das causas mais óbvias dessa injustiça é causada pela arbitrariedade moral associada ao sistema de distribuição de posicionamentos sociais tomados como dados na reprodução social. A distribuição de vantagens e desvantagens depende da capacidade produtiva dos seus membros, o que em uma sociedade capitalista depende, por sua vez, de quanto o mercado de trabalho valoriza os talentos e habilidades de uma pessoa. Contudo, talentos e habilidades adquiridas são fatores moralmente arbitrários em nossas vidas. Elas encontram-se sujeitas a circunstâncias biológicas e sociais que escapam ao nosso controle individual, e sobre as quais não possuímos nenhum tipo de agência. A instituição da família, as desigualdades sociais acumuladas no tempo (classe, família, raça, gênero etc.), o espaço ocupado 
(bairro, região, hemisfério etc.), e o valor de mercado de certas aptidões naturais tidas por "rentáveis" em uma sociedade de mercado, são exemplos de fatores moralmente arbitrários em nossas vidas 9 . Essas são características individuais distributivamente determinantes, mas que começam a operar em nossas vidas muito antes de nos tornarmos agentes morais independentes. É nesse sentido que podemos afirmar que qualquer forma de igualitarismo recusará a escolha do "prêmio" do mercado como critério justo de distribuição dos recursos sociais.

Quanto a esse ponto, não existem grandes discrepâncias entre as diferentes formas de igualitarismo. Se todas as pessoas precisam ser tratadas como iguais, então é natural que reivindiquemos alguma forma de igualdade material entre todas as pessoas. $\mathrm{O}$ desacordo começa quando precisamos especificar os parâmetros distributivos da igualdade material. É aqui que o igualitarismo de fortuna evoca o problema da exploração interpessoal: se os nossos juízos sobre a injustiça são embasados na impossibilidade de atribuirmos responsabilidade sobre fatores moralmente arbitrários em nossas vidas, então "em deferência à equidade" (Cohen, 2011:121), deveríamos também aceitar como justas as desigualdades produzidas por decisões voluntárias. Se somos contrários à desigualdade porque ela é fruto do acaso, então temos que aceitar como justas aquelas formas de desigualdade que são causadas somente pelas decisões voluntárias das pessoas. Caso os princípios distributivos possam ser formulados com base na igualdade de oportunidade para resultados igualitários, distribuindo o acesso aos bens socialmente valiosos e não um resultado distributivo qualquer, então temos uma teoria igualitária à prova de exploração interpessoal.

\section{O IGUALITARISMO DE FORTUNA}

Chamando de "métrica" o tipo de bem que as teorias da justiça almejam para tornar as pessoas iguais, e por "parâmetro" os critérios mais adequados para uma distribuição igualitária, as variedades de concepções distributivas podem ser organizadas com base na combinação das respostas possíveis para (I) e (II). Ou seja, podemos organizá-las com base nas diferentes métricas distributivas, de um lado, e nos parâmetros para distribuição, de outro. Deixando de lado as métricas mistas, que misturam diferentes métricas e parâmetros, temos quatro possibilidades diferentes de igualdade distributiva: 
Quadro 1

Tipos de Igualdade Distributiva

Métrica

\begin{tabular}{|c|c|c|c|}
\hline \multirow{3}{*}{ Parâmetro } & & Objetiva & Subjetiva \\
\hline & Resultado & $\begin{array}{l}\text { (a) Igualdade de resultados de } \\
\text { recursos }\end{array}$ & $\begin{array}{l}\text { (c) Igualdade de resultados de } \\
\text { bem-estar }\end{array}$ \\
\hline & Oportunidade & $\begin{array}{l}\text { (b) Igualdade de oportunidade } \\
\text { para recursos }\end{array}$ & $\begin{array}{l}\text { (d) Igualdade de oportuni- } \\
\text { dade para bem-estar }\end{array}$ \\
\hline
\end{tabular}

Com base no Quadro 1, podemos afirmar que igualitarismo de fortuna é composto pelas concepções de justiça que se encaixam nos quadrantes (b) e (d). As teorias agrupadas em (a) e (c) representam as variantes tradicionais de justiça igualitária, respectivamente, a igualdade (simples) de recursos e as teorias utilitaristas. O que (b) e (d) possuem em comum é o reconhecimento do problema que a exploração dos mais produtivos acarreta para o igualitarismo, e sua solução com base em critérios distributivos sensíveis à responsabilidade individual. Enquanto as teorias fortunistas podem variar em relação à métrica adotada, elas concordam em relação à adoção de parâmetros distributivos orientados para a estrutura de oportunidades - e não para os resultados - de arranjos distributivos. Meu objetivo nesta seção é ilustrar a relevância dessa tipologia com base na reconstrução das duas teorias mais importantes do igualitarismo de fortuna: a igualdade de oportunidade para recurso proposta por Ronald Dworkin, uma concepção de tipo (b); e a igualdade para bem-estar individual proposta por Richard Arneson, uma concepção igualitária de tipo (d).

\section{Igualdade de Oportunidade para Recursos}

Em dois célebres artigos publicados na década de 1980, Dworkin apresentou uma teoria de igualdade de oportunidades crucial para os desenvolvimentos do igualitarismo de fortuna (Dworkin, 1981a, $1981 b)^{10}$. Não é exagero afirmar que essa contribuição balizou os debates teóricos subsequentes no interior do igualitarismo. $\mathrm{O}$ fez a tal ponto que Cohen chegou a afirmar que Dworkin teria realizado um serviço único para o igualitarismo "na medida em que incorporou a essa tradição a ideia mais poderosa do arsenal da direita anti-igualitária: as noções de escolha e responsabilidade [individuais]" (Cohen, 1989:933). O pressuposto fundamental de Dworkin é similar ao argumento já esboçado na seção anterior: o igualitarismo sustenta que as pessoas 
devam ser tratadas como iguais e, tradicionalmente, essa exigência é satisfeita quando garantimos um controle equitativo de recursos materiais entre as pessoas (Dworkin, 1981a:186). Contudo, devemos revisar essa versão simples de igualitarismo para que ela não incorra na exploração dos membros mais produtivos da sociedade.

O primeiro passo do argumento dworkiniano é descartar a principal alternativa teórica à igualdade (simples) de recurso, qual seja, a igualdade de satisfação de bem-estar. Dworkin procura mostrar que teorias welfaristas são conceitualmente implausíveis como base normativa para o igualitarismo, uma vez que exigem que as pessoas sejam tratadas como iguais em relação ao grau de satisfação subjetiva obtido por cada indivíduo. À primeira vista, essa é uma perspectiva atraente para o igualitarismo. Afinal, métricas subjetivas seriam capazes de separar o valor de um recurso, como uma quantia monetária qualquer, do quão importante essa quantia é para cada indivíduo em particular. Uma mesma quantia de recursos teria efeitos de satisfação bem diferentes para um poeta apaixonado por sua profissão, para um banqueiro milionário, e para uma mãe solteira desempregada. Não obstante esse apelo, Dworkin apresenta uma dificuldade conceitual crucial para propostas de equalização de bem-estar: a inescapável disseminação de preferências sobre o bem-estar alheio. Preferências ditas externas são preferências sobre o comportamento e os desejos de outros sujeitos ou grupos sociais, ou mesmo preferências sobre a organização da sociedade como um todo. Desse modo, contrastam com o tipo de preferência pressuposta pelas teorias welfaristas, as preferências internas e auto-orientadas. Em sua crítica à igualdade de bem-estar, Dworkin procura mostrar, em primeiro lugar, que a tentativa de equalizar preferências externas pode se revelar uma tarefa extremamente difícil do ponto de vista igualitário, e, em seguida, que o utilitarismo não oferece um critério aceitável para excluirmos essas preferências da agregação social. Teorias welfaristas nos obrigariam a compensar distributivamente indivíduos adeptos a ideias anti-igualitárias (como grupos racistas, xenófobos, ou setores elitistas da sociedade), por sua perda de bem-estar causada pelos infortúnios subjetivos de viverem em uma sociedade mais igualitária. Seríamos obrigados, no limite, a compensar defensores da submissão feminina pelo "sofrimento" causado pela distribuição igualitária de recursos entre homens e mulheres. 
Se a igualdade de bem-estar é um ideal inaceitável porque conceitualmente incoerente, a igualdade (simples) de recursos, como vimos, tende a produzir relações opressivas entre pessoas com perfis de produtividade distintos. Dworkin argumenta que o igualitarismo convencional é incapaz de lidar com o "problema dos gostos caros" que, para os propósitos deste artigo, pode ser entendido como uma forma de exploração interpessoal.

Imaginemos o caso de uma pessoa, o Luiz, que deliberadamente optou por cultivar gostos ou ambições que, até então, ele não possuía. No exemplo original, Luiz adquire o hábito de comer ovos de tarambola e degustar vinhos de uvas pré-filoxéricas, ao invés de ovos de galinha e cerveja nacional (Dworkin, 1981b:229) ${ }^{11}$. O exemplo escolhido por Dworkin, contudo, pode nos levar a dar ênfase excessiva ao caráter frívolo, ou mesmo arbitrário, do novo gosto adquirido. Na verdade, o que importa para o argumento é ilustrar uma ambição ou preferência pessoal cara e não uma escolha arbitrária ${ }^{12}$. Podemos aprimorar o exemplo fazendo com que a nova escolha de Luiz seja por uma carreira política dedicada a uma causa honorável - como, por exemplo, salvar as tarambolas do risco de extinção. Ou ainda, dedicando-se a uma vida mais edificante, como uma vida sem patrão, ou sem seu enfadonho emprego de corretor no centro da cidade. Essas são opções perfeitamente defensáveis do ponto de vista dos valores e conviç̧ões de Luiz. Mas essas são também escolhas que tornam a sua vida mais cara do que a vida que tinha antes. A pergunta então é: de um ponto de vista igualitário, é justo que a sociedade compense as novas preferências de Luiz? A resposta dworkiniana é depende. "[A] verdadeira medida dos recursos sociais devotados à vida de cada pessoa", afirma Dworkin, "é estabelecida perguntando-se quão importante, de fato, esses recursos são para os outros" (2005:70, ênfase minha). Caso possamos demonstrar que as novas reivindicações distributivas de Luiz são fruto de fatores moralmente arbitrários em sua vida, constituindo desvantagens não-merecidas, a sociedade teria o dever de compensá-lo distributivamente. Caso essas escolhas representem escolhas deliberadas de um agente autônomo (como o exemplo dos gostos caros procura ilustrar), a sociedade não deveria ser onerada por isso. Essas são escolhas cujo ônus os próprios agentes deveriam arcar.

Podemos reconstruir o argumento geral do igualitarismo de fortuna dworkiniano em três passos. Em primeiro lugar, Dworkin estabelece um corte conceitual entre casos de sorte "bruta", compostos por 
contingências fora de nosso controle intencional, e os casos de sorte "opcional", resultantes de deliberações calculadas sobre um dado curso de ação (Dworkin, 1989b:293). O segundo passo é garantir que as instituições de uma sociedade igualitária compensem apenas os custos distributivos das circunstâncias involuntárias (sorte bruta), deixando os custos das escolhas voluntárias para seus próprios agentes (sorte voluntária). Caso a distribuição dos recursos sociais atenda a essa exigência, então podemos afirmar com segurança que estamos diante de uma distribuição ao mesmo tempo igualitária e livre de exploração. Notemos que com isso Dworkin - e o igualitarismo de fortuna de modo geral - está defendendo dois parâmetros normativos simultâneos: (1) precisamos compensar casos de má sorte involuntária; e (2) devemos punir distributivamente escolhas voluntárias onerosas. Como afirma Dworkin, "a igualdade de [oportunidade para] recursos exige que as pessoas paguem o verdadeiro preço do tipo de vida que elas escolhem levar" (1981b:295).

Isso nos leva ao terceiro e último passo do argumento. Dworkin defende que os critérios distributivos de uma sociedade justa sejam concebidos como um mercado de seguros hipotéticos, responsável por compensar, no sentido atuarial, desvantagens individuais moralmente arbitrárias. A ideia é tão simples quanto poderosa: mercados reais de seguro são mecanismos alocativos que convertem casos de sorte bruta individual em sorte opcional, isto é, eles transformam o acaso em um problema de responsabilidade individual. Se, por exemplo, invisto meu tempo e meus recursos na construção de uma casa, e uma enchente inesperada a destrói, sofro um duro golpe de má sorte. Por outro lado, caso tivesse comprado uma apólice de seguro contra enchentes, o mesmo acontecimento converter-se-ia em um tipo opcional de risco, um risco que, em certo sentido, aceito deliberadamente incorrer. O problema, evidentemente, é que o tipo de má sorte contra o qual precisamos nos assegurar em contextos de justiça social não têm semelhança com o tipo de produto vendido em um mercado de seguros. Nascer no bairro com o pior IDH (Índice de Desenvolvimento Humano) do município, ser portador de uma doença rara, ou ainda não ter as aptidões esperadas pelo mercado de trabalho, é um tipo de azar que começa a funcionar antes mesmo que os indivíduos possam escolher deliberadamente o tipo de risco que querem assumir em suas vidas. Simplesmente não podemos esperar que um mercado de seguros compense as pessoas depois que os infortúnios indesejados já aconteceram. 
A solução oferecida por Dworkin é imaginar um mercado de seguro hipotético no qual as pessoas poderiam aderir antes mesmo de saberem qual o tipo específico de vida que levarão. Voltemos ao nosso exemplo. A escolha de Luiz por uma vida sem patrão, por mais significativa que seja para a sua concepção pessoal de felicidade, não justifica por si só um montante maior de recursos sociais do que as pessoas que, voluntariamente, optaram por continuar a trabalhar. A situação seria diferente, contudo, caso o mesmo montante de recursos fosse necessário para financiar sua perda involuntária de emprego causada por uma crise econômica, ou pelo fato de suas habilidades profissionais terem se tornado obsoletas no mercado de trabalho. A diferença entre os dois casos de redução de esforço produtivo é que desemprego e obsolescência de talentos representam riscos normais de uma sociedade capitalista. Riscos esses que, segundo a teoria de Dworkin, qualquer pessoa teria interesse em adquirir uma apólice de seguros social hipotética. O mercado de seguros hipotéticos nos permite entender, afinal, por que o igualitarismo de fortuna é, a rigor, uma teoria de igual oportunidade para alguma coisa: o objeto da justiça, aquilo em relação ao que as pessoas precisam para ser igualadas, são as oportunidades equitativas de acesso aos recursos sociais, e não os próprios recursos sociais.

\section{Igualdade de Oportunidade para Bem-Estar}

A teoria distributiva de Richard Arneson também encontra na igualdade de oportunidade seu conceito central. Mas no caso de Arneson, a métrica adequada para justiça igualitária é a igualdade de oportunidade para bem-estar (Arneson, 1989). A despeito das objeções de Dworkin ao utilitarismo, Arneson explora um espaço conceitual não considerado pelas teorias da justiça convencionais: o espaço ocupado por teorias simultaneamente welfaristas e sensíveis à responsabilidade individual dos agentes. O objetivo do igualitarismo de fortuna de Arneson (2002) é demonstrar que Dworkin tem razão ao reformular o ideal igualitário com base em uma teoria de igualdade de oportunidade - rejeitando, portanto, as teorias em (a) e (c) -, mas a melhor métrica distributiva da justiça é o acesso a perfis socialmente determinados de satisfação de preferências individuais (d).

O argumento dworkiniano de que a equalização de bem-estar é conceitualmente incoerente seria, para Arneson, apenas uma má caracterização do significado normativo das nossas preferências individuais 
(Arneson, 1989, 2002). Arneson argumenta que existem dois elementos conceituais diferentes em operação nas nossas escolhas: o elemento volitivo e o elemento valorativo. Se prefiro $x$ a $y$, o elemento volitivo me diz que eu quero mais $x$ do que $y$. Contudo, essa não seria a única dimensão relevante de uma preferência. Escolhas deliberadas pressupõem a capacidade de avaliar e, portanto, julgar de um ponto de vista normativo, as opções disponíveis. Se eu prefiro $x$ a $y$, então, além do elemento volitivo, eu também julgo ou avalio normativamente que $x$ é mais valioso do que $y$. Os dois elementos nem sempre estão em acordo. Alguém pode desejar $x$, mas, após deliberar sobre a questão, concluir que, a despeito de seus desejos, $y$ é o certo a se fazer. Em princípio, esse resultado não altera o fato de continuarmos a querer $x$, mesmo sabendo que seria uma decisão equivocada. Por exemplo, posso preferir mais um banho gelado de piscina a terminar um artigo de filosofia moral, em uma tarde quente de domingo. Contudo, também sou capaz de ponderar o resultado dessa escolha, atentando para o fato de que não terminar o artigo trará consequências indesejadas no longo prazo, como um péssimo desempenho no colóquio programado para o final do mês. Caso eu não resista à tentação da piscina, e não termine o artigo, a insatisfação posterior que sentirei com o fiasco no colóquio será muito pior do que passar calor no presente. Ou seja, posso ponderar o elemento volitivo das minhas preferências com base em considerações prudenciais mais abrangentes. Agentes racionais avaliam e reformulam padrões de preferência permanentemente e, portanto, seria um erro confundir uma preferência racionalmente ponderada com uma simples volição irrefletida.

Arneson argumenta, então, que precisamos conceber as preferências individuais em seu aspecto prudencial mais amplo: as preferências que importam para uma teoria da justiça são as preferências que podem ser formuladas e revisadas ao longo do tempo - o que Arneson denomina de "preferências racionais" (2002:186). Reconhecer esse ponto nos permite solucionar alguns curtos-circuitos conceituais levantados por Dworkin. Dessa perspectiva, os agentes são capazes de deliberar sobre suas próprias preferências, não precisando tomá-las simplesmente como dadas. Quando bem entendida, a satisfação de preferência pode informar uma teoria distributiva na forma de uma igualdade de oportunidade para bem-estar individual. Essa igualdade exige que as pessoas sejam tratadas como iguais em relação aos diferentes perfis de satisfação de preferências individuais disponíveis em uma sociedade. "Realizamos a igualdade de oportunidade para bem-estar entre as 
pessoas", explica Arneson, "quando garantimos que todas as pessoas possuem diante de si um conjunto de decisão de possibilidades de vida equivalentes [isto é], quando o valor esperado da melhor decisão de cada uma dessas matrizes de escolha [...] é o mesmo" (Arneson, 2002:189) $)^{13}$.

Vejamos o que isso significa. Aceitemos que duas pessoas, Júlio e Júlia, estejam em condições idênticas de oportunidade, no momento de decidirem suas carreiras profissionais. Ambos precisam escolher, por exemplo, se querem ou não cursar ensino superior, e em caso afirmativo, qual carreira gostariam de seguir, se, digamos, será teatro ou engenharia aeroespacial. Cada uma das escolhas (teatro, engenharia, ou curso nenhum) implica um padrão de bem-estar diferente para cada um deles ao longo de suas vidas. Digamos que Júlia decida ser engenheira enquanto Júlio opte por ser ator. Cada decisão exigirá um montante de recursos e investimento pessoal diferente. Digamos ainda que os dois tenham sucesso em suas carreiras e que, com base em suas preferências, ambos obtenham o mesmo bem-estar. Os percursos relativos de cada formação, e o montante de recursos necessários para cada escolha foram bem diferentes, mas, ao final, o critério de satisfação proposto por Arneson diria que Júlio e Júlia foram tratados de modo igualitário: nenhum dos dois trocaria voluntariamente o seu perfil de satisfação pelo do outro.

Consideremos, diferentemente, o caso em que eles não estejam satisfeitos com os resultados de suas escolhas e que seus perfis de bem-estar tenham se tornado muito desiguais. Digamos que Júlio tenha dedicado mais tempo perambulando pelos bairros boêmios da cidade do que frequentando seus ensaios e, consequentemente, tenha sido preterido em todos os papéis disponíveis. Júlia, por outro lado, tornou-se uma brilhante cientista e está trabalhando na universidade de seus sonhos. Nesse segundo cenário, o bem-estar de Júlio é bem inferior ao de Júlia. Contudo, essa é uma desigualdade em relação a qual não devemos esperar uma compensação. Afinal, ela é fruto exclusivo da irresponsabilidade de Júlio, ou seja, de sua má sorte "escolhida" pela vida de boêmio. De acordo com o igualitarismo de fortuna de Arneson, Júlio só possuiria uma reivindicação distributiva legítima contra Júlia caso suas fortunas pessoais não voluntárias fossem assimétricas. Por exemplo, caso Júlio não pudesse escolher uma vida com curso superior apenas por ter nascido em uma família sem os recursos materiais necessários para financiar a sua escolha. 


\section{O CORTE CONCEITUAL}

O que há de errado, então, com o igualitarismo de fortuna? Uma primeira objeção se refere à estabilidade do corte conceitual entre circunstâncias não voluntárias e escolhas voluntárias. Se o igualitarismo de fortuna tem como ponto de partida conceitual a diferença entre reivindicações distributivas legítimas (porque involuntárias) e ilegítimas (porque voluntárias), ele precisa encontrar um modo sistemático de rastrear a gênese das reivindicações, para saber se elas se encontram nas circunstâncias ou nas escolhas de uma pessoa. Trata-se, portanto, de uma crítica conceitual: o ponto é mostrar que qualquer decisão sobre onde deveríamos aplicar o corte produz consequências teóricas controversas para o igualitarismo de fortuna.

É verdade que diferentes versões de igualitarismo de fortuna oferecem cortes conceituais distintos. Tomando como base de comparação as noções usuais de responsabilização nas democracias liberais, é possível afirmar que Dworkin e Arneson propõem, respectivamente, uma estratégia de corte conservadora e uma radical ${ }^{14}$. A crítica interna sustenta, contudo, que estratégias de corte conservadoras (Dworkin) produzem resultados distributivos frustrantes para uma teoria igualitária, enquanto estratégias radicais (Arneson) tendem a produzir formas extremamente controversas de atribuição de responsabilidade individual.

Tomemos como exemplo uma situação de negligência opcional. Imaginemos que uma pessoa, com um problema grave de saúde, reivindique recursos públicos já que possui uma necessidade especial de locomoção. Digamos também que, a despeito de ser um problema grave no presente, a doença poderia ter sido controlada no passado, caso a pessoa tivesse dedicado atenção aos seus primeiros sintomas. $\mathrm{O}$ igualitarismo de fortuna afirma que o caso deveria ser considerado uma circunstância involuntária a depender das escolhas feitas por essa pessoa. Entretanto, quando tomamos a cadeia completa de decisões ao longo de uma vida é extremamente difícil responder essa questão de modo decisivo.

Fundado em um corte conceitual conservador, o modelo de mercado de seguros de Dworkin prescreveria a não cobertura em casos de negligência opcional como esse. É relativamente simples mostrar que as pessoas não se assegurariam contra perdas materiais facilmente evitáveis por mudança de comportamento. Nesse sentido, Dworkin está correto ao 
afirmar que seu critério encontra respaldo em certos padrões vigentes de atribuição de responsabilidade individual. O problema é que, segundo esses mesmos critérios, as vantagens e desvantagens naturais de uma pessoa também deveriam ser interpretados como casos de negligência opcional em potencial. $\mathrm{O}$ argumento é exatamente o mesmo, mas tendo como objeto um talento e não uma deficiência: o florescimento de habilidades e talentos individuais são contabilizados indiretamente contra cenários de negligência opcional nos quais decidimos "deliberadamente" por não os cultivar. O que nos impede de afirmar que pessoas pouco talentosas (em princípio, passíveis de recompensa no modelo de Dworkin) não devem ser concebidas como pessoas que optaram sistematicamente por não cultivar suas verdadeiras potencialidades ao longo de suas vidas? Se esse for o caso, então pessoas pouco produtivas poderiam ser plenamente responsáveis por seu baixo quinhão distributivo. A linha de corte conservadora nos leva perigosamente em direção à visão anti-igualitária, de acordo com a qual os pobres são responsáveis por sua miséria.

Arneson procura evitar esse problema caracterizando o próprio processo de formação das preferências individuais como parte das circunstâncias fortuitas às quais estamos sujeitos ao longo de nossas vidas. O modo como desenvolvemos certos gostos e preferências por vezes são tão pouco intencionais quanto nossas aptidões e habilidades naturais. Com isso evitamos o caso da negligência por opção. Todavia, incorrermos agora em um problema contrário: aspectos importantes de nossas vidas, como nossos comprometimentos morais e aspectos de nossa identidade pessoal, precisariam ser compensados como um tipo de desvantagem social oneroso. Se aceitarmos que um fiel tem direito à subvenção de suas preferências porque foi criado como tal, isto é, por razões que fugiriam ao seu controle, teríamos que, coerentemente, recusá-la para féis que, crescendo em contextos secularizados, tenham se convertido a essas mesmas religiões. Contudo, essa seria uma solução duplamente controversa. Para um fiel de nascimento, sua crença religiosa seria publicamente interpretada como um tipo de circunstância desvantajosa involuntária, ofendendo a sua identidade social. Para um fiel convertido, o significado subjetivo de sua conversão seria publicamente interpretado como uma preferência onerosa, desrespeitando o caráter ético de sua conversão. Em outras palavras, a estratégia radical de Arneson apresenta dificuldade em oferecer uma base pública de reivindicação distributiva que respeite decisões fundantes da nossa identidade pessoal. Tratar identidades 
e comprometimentos morais valiosos como formas de desvantagem social involuntária pode significar tratar as pessoas como incapazes de governar suas próprias vidas.

\section{DESRESPEITO E DISTRIBUIÇÃO}

A crítica conceitual, ou interna, ao igualitarismo de fortuna certamente possui alguns méritos para o programa de pesquisa igualitário. Dentre eles está a cobrança de um tratamento mais sofisticado das noções de preferência individual e responsabilidade pessoal.

Entretanto, o problema do corte não é um problema mais grave no igualitarismo de fortuna do que em qualquer outra concepção de justiça que aceite a arbitrariedade moral na distribuição de posicionamentos sociais. Existe um segundo tipo de objeção segundo o qual mesmo que fosse possível solucionar esse problema, ainda assim o igualitarismo de fortuna não faria justiça ao ideal igualitário. Na medida em que essa crítica procura disputar o significado normativo do ideal igualitário, e correndo o risco de uma formulação pouco elegante, podemos denominá-la como crítica igualitária ao igualitarismo de fortuna. Essa crítica tem como ponto de partida a resistência em conceber o valor moral da igualdade em termos estritamente distributivos. Essa resistência é encontrada na afirmação de Samuel Scheffler, segundo a qual "relações igualitárias [devem ser] caracterizadas em termos práticos e deliberativos em vez de em termos distributivos" (Scheffler, 2015:31). Ou ainda, que "igualitários [e igualitárias] não devem ser motivados apenas por uma preocupação com a equidade distributiva, mas também pela ideia de respeito por todos e todas" (Wolff, 1998:97). Essa também é a definição dos objetivos morais do igualitarismo privilegiada por Elizabeth Anderson (1999:313). "[D]e um ponto de vista negativo", afirma, "igualitários [e igualitárias] almejam abolir a opressão - isto é, formas de relações sociais com base nas quais as pessoas dominam, exploram, marginalizam, aviltam e exercem violência umas sobre as outras". O valor das teorias igualitárias estaria na tentativa de conceber "uma ordem social na qual as pessoas mantenham relações de igualdade entre si" (Anderson, 1999:313).

Em contraposição ao que entendem por igualdade distributiva, esses autores e autoras argumentam que o igualitarismo é mais bem entendido com base em uma visão relacional do valor da igualdade e que, consequentemente, essa visão nos autoriza a elaborar e defender um tipo relacional de igualitarismo. Desse modo, duas pessoas são iguais 
na medida em que não estabelecem relações de hierarquia e dominação injustificada umas sobre as outras. Ou, de maneira inversa, na medida em que são capazes de estabelecer relações pautadas pelo respeito mútuo entre iguais. A igualdade é concebida como um valor relacional, cujas aspirações práticas são mais bem entendidas com base em um ideal político e social responsável por governar nossas relações interpessoais. A visão relacional da igualdade não desconsidera a importância de problemas distributivos. Contudo, reivindicações distributivas são importantes na medida em que permitem ou atrapalham o estabelecimento de relações sociais igualitárias. Desigualdades econômicas caracterizam instâncias importantes de desrespeito e exploração. Além disso, desigualdades de renda e riqueza são um indicador importante de relações sociais hierarquizadas e podem, por si só, constituir um tipo específico de dominação social ${ }^{15}$. A diferença é que, para a visão relacional, o valor da igualdade não é ele mesmo um valor essencialmente distributivo, mas sim um ideal de sociedade.

Não é o meu objetivo neste artigo apresentar uma teoria completa do igualitarismo relacional ${ }^{16}$. Meu ponto é mais modesto: gostaria de demonstrar que uma crítica à visão da igualdade pressuposta pelo igualitarismo de fortuna pode trazer pelo menos duas consequências importantes para a agenda de pesquisa igualitária.

A primeira delas é a possibilidade de explicar o erro do igualitarismo de fortuna como um problema propriamente teórico, e não apenas como uma dificuldade natural ligada à natureza do livre-arbítrio, ou ainda ao contexto político-econômico nos quais essas teorias foram produzidas (voltarei a essa segunda crítica adiante). Em segundo lugar, e talvez mais importante, a crítica relacional do igualitarismo de fortuna nos permite avaliar o modo como a própria agenda de pesquisa igualitária tem sido concebida nas últimas décadas. Como já afirmado, uma das prioridades dessa agenda é responder ao problema da exploração interpessoal. Contudo, ao enfatizar o papel do respeito mútuo nas teorias da justiça, o igualitarismo relacional nos obriga a responder uma pergunta diferente daquela sobre a exploração interpessoal, a saber, como devemos conceber os sujeitos da justiça? Isto é, o que devemos umas às outras enquanto pessoas livres e iguais? Como procurarei mostrar, identificar esse segundo problema como equivalente ao problema da exploração interpessoal restringe de modo controverso algumas categorias centrais das teorias igualitárias, como as noções de agência e responsabilidade pessoal. 
No restante deste artigo procurarei corroborar as duas afirmações demonstrando que a visão relacional da igualdade é distinta da distributiva. O objetivo é mostrar não apenas que o fundamento normativo das teorias relacionais é diferente, como também que ele não pode ser expresso adequadamente pelo igualitarismo de fortuna - pelo menos em sua formulação atual. A principal razão para enfatizar que formas relacionais de igualdade representam um ideal normativo alternativo à igualdade distributiva repousa na constatação de que uma distribuição equitativa não é o único aspecto normativo importante de uma teoria igualitária.

Temos boas razões para considerar que o respeito mútuo entre iguais constitui uma dimensão imprescindível do ideal igualitário. Em primeiro lugar, por que relações sociais fundadas no respeito mútuo são, no mínimo, tão importantes para o igualitarismo quanto alcançar padrões de equidade distributiva entre as pessoas. Existem várias formas pelas quais as pessoas podem ser desrespeitadas em suas relações sociais, variando desde convenções sociais informais até a institucionalização de tratamentos desrespeitosos. Uma sociedade é injusta de um ponto de vista igualitário seja quando permite desigualdades distributivas arbitrárias entre seus cidadãos, seja quando permite a reprodução de relações assimétricas arbitrárias - como a opressão política, a exclusão social e a exploração econômica. Para a visão relacional, o que há de comum nesses dois casos de injustiça é a incapacidade da sociedade de tratar a todos e todas como iguais em respeito. Além disso, uma vez que reconhecemos o respeito mútuo como um valor igualitário igualmente fundamental, não podemos descartar de antemão que mesmo uma distribuição perfeitamente equitativa de recursos sociais poderia tratar os sujeitos da igualdade de forma desrespeitosa. É inquestionável que formas injustas de distribuição devam ser entendidas como um caso importante de desrespeito. Contudo, mesmo uma sociedade equitativamente justa na distribuição de recursos não estaria, no limite, livre de instâncias estruturais de desrespeito. Isso porque para qualquer ideal distributivo (ou para os meios institucionais necessários derivados desse ideal) sempre poderemos nos perguntar se ele possui consequências nocivas para as bases interpessoais do respeito mútuo ou do autorrespeito pessoal ${ }^{17}$.

Um tipo particularmente grave de desrespeito distributivo é a organização de sistemas distributivos com base em escrutínios públicos vexatórios (Anderson, 1999; Wolff, 1998) ${ }^{18}$. O igualitarismo de fortuna 
estabelece uma relação moralmente problemática entre a legitimidade de nossas reivindicações distributivas e a necessidade permanente de averiguação pública das desvantagens pessoais. Ou seja, mesmo que pudéssemos estabelecer o corte conceitual esperado, ainda assim o igualitarismo de fortuna traria consequências potencialmente injustas para relações baseadas no respeito mútuo. Escrutínios públicos são necessários para o igualitarismo de fortuna na medida em que, para podermos distribuir recursos de acordo com a sorte merecida de cada pessoa, precisamos, antes de tudo, tipificar os cidadãos e cidadãs em relação às escolhas pessoais realizadas ao longo de suas vidas. No que diz respeito às pessoas menos beneficiadas pela cooperação social, isso pode significar duas coisas: ou elas se encontram nessa posição devido a circunstâncias involuntárias, ou por responsabilidade própria. Em ambos os casos a averiguação pública fundada em critérios fortunistas pode gerar efeitos graves de estigmatização social.

Para as vítimas da má sorte opcional, o escrutínio significa o reconhecimento de sua responsabilidade pela situação em que se encontra. Imaginemos, por exemplo, um grupo de jovens aficionados por corridas de carro que, contra a lei, organizam rachas nas ruas da cidade pela madrugada. Essa é uma decisão a qual as pessoas devem ser responsabilizadas. Como vimos, o igualitarismo de fortuna nos leva a concluir que, em casos como esse, os motoristas irresponsáveis não deveriam ser penalizados apenas juridicamente por terem desrespeitado as leis de trânsito, mas também punidos distributivamente em casos de acidentes. Com isso poderíamos, por exemplo, negar a assistência e o tratamento médico público a essas pessoas. Ou, caso o acidente traga consequências indesejadas para o seu potencial produtivo futuro, que elas sejam excluídas de benefícios previdenciários. Suas vidas a partir desse ponto serão marcadas como um tipo de fracasso "merecido", um destino pelo qual a sociedade pode ter pena, mas não obrigações distributivas. Como afirma Anderson (1999:295-302), talvez nem mesmo os imprudentes convictos mereçam um destino tão cruel como esse.

Contudo, a institucionalização da igualdade de fortuna acarreta um tipo de humilhação pública mesmo para quem possui uma reivindicação legítima à redistribuição de recursos nos critérios da igualdade de fortuna. Para as vítimas de má sorte bruta, a redistribuição implicaria o reconhecimento público de que seus beneficiários dependem da ajuda dos membros mais favorecidos pela cooperação social, colocando em 
risco seu senso de autorrespeito enquanto um(a) igual. Isso porque o modelo estabelece uma assimetria de justificação entre ricos e pobres. Como afirma Jonathan Wolff, "o fardo da revelação [pública] de informação pessoal recai apenas sobre um setor da sociedade, um setor que já é publicamente reconhecido como o que possui maior desvantagem social", enquanto "o rico não tem que explicar como se tornou rico" (Wolff, 1998:111). Para entender melhor esse mecanismo, basta imaginar uma pessoa cujos talentos e habilidades não sejam valorizados pelo mercado de trabalho. Um sistema institucionalizado de escrutínios públicos detectaria os indivíduos em desvantagem social e, uma vez confirmada uma circunstância distributivamente arbitrária, caberia ao Estado indenizá-los por isso. Com base nessa crítica, e tomando o mercado hipotético de seguros como exemplo, Elizabeth Anderson imagina a seguinte carta de compensação de um Ministério da Seguridade Social imaginário:

Infelizmente, as outras pessoas não valorizam o pouco que você tem a ofertar para o sistema de produção social. Seus talentos foram avaliados e considerados exíguos demais para gerar uma remuneração de mercado satisfatória. Devido a má sorte em ter nascido tão pobremente provido de talentos, nós, os produtivos e produtivas, retificaremos essa desvantagem: permitiremos que partilhe de um quinhão de riqueza social produzida por meio do emprego das nossas habilidades vastamente superiores e, portanto, muito mais valorizadas (Anderson, 1999:305).

Os beneficiários (legítimos) de políticas redistributivas precisariam revelar publicamente que, frente aos seus concidadãos, eles são de fato menos talentosos e menos capazes de contribuir para a riqueza social. Os beneficiários desse sistema precisam demonstrar, permanentemente, que são merecedores da ajuda da sociedade. Em um relato recente sobre o problema da fome nos EUA, Martín Caparrós (2014:390) capturou de modo preciso o mecanismo de estigmatização presente em certas políticas públicas distributivas: 
Mareshka cuida [da] loja - cerveja, cigarros, jornais, bilhetes de loteria, guloseimas - de uma prima e ganha uns 2 mil [dólares] por mês. Seus três filhos têm entre 13 e 21 anos de idade.

- Vivem querendo comer. O que quer que lhes dê?

- Mas, com essa renda, não tem o direito de pedir ajuda, vale-comida [food stamps]?

- Sim, tenho direito, mas não tenho vontade. Não quero. Ganho minha vida, não quero que ninguém me dê nada de presente [...] I'm American, diz.

O ônus da justificação assimétrica explica por que, em regimes de bem-estar reais, cidadãos em pior situação distributiva optam por não reivindicar benefícios distributivos legítimos, mesmo quando possuem plenos direitos de fazê-lo. A razão pela qual as pessoas sofrem estigma social em casos como esse é derivada do tipo de relação em que se encontram, e não apenas do quanto essas pessoas possuem.

O vocabulário distributivo tende a caracterizar todos os problemas de justiça como problemas de distribuição equitativa de recursos passíveis de apropriação privada. Isso faz com que tendamos a avaliar a presença de bens sociais não distribuíveis, como a ausência de relações sociais assimétricas, como instâncias de distribuição desigual de algo, como por exemplo, liberdade ou poder. Dworkin, por exemplo, concebe o problema da igualdade política como equivalente a considerar sobre "de que modo o princípio [de igual consideração] possui consequências para a questão fundamental de como devemos distribuir o poder político em uma dada comunidade" (1987:2, ênfase minha). Arneson, por sua vez, define o problema da liberdade religiosa como equivalente ao colocado por "uma distribuição equitativa (igual) dos recursos da liberdade religiosa" (1989:80). Ou seja, para o igualitarismo de fortuna, a caixa de ferramenta igualitária acaba sendo composta exclusivamente por princípios distributivos, negligenciando outras categorias igualitárias importantes, como direito, poder e mútuo/autorrespeito. A reivindicação de igualdade de direitos não demanda a distribuição de um mesmo direito para todas as pessoas, mas que a relação de igualdade entre as pessoas seja tomada como o critério de avaliação de suas interações (Young, 1990). Não podemos distribuir o valor de possuir direitos porque, do ponto de vista igualitário, é justamente a posição de igualdade de reivindicações que serve como critério para distribuições justas e injustas. 


\section{IGUALDADE SOCIAL E RESPONSABILIDADE PESSOAL}

Teorias da justiça como as de Dworkin e Arneson possuem duas características centrais. Por um lado, elas enfatizam o princípio de igualdade de oportunidade e o valor da responsabilidade individual; por outro, rejeitam a interpretação libertariana convencional desses conceitos, segundo a qual é suficiente, do ponto de vista da justiça, que posições de prestígio e poder sejam distribuídas de acordo com procedimentos imparciais (Hayek, 1960; Mankiw 2011). Como procurei mostrar, o igualitarismo de fortuna reconhece que distribuições desiguais de recursos (ou bem-estar) são justas se, e apenas se, tais desigualdades resultem de nossas escolhas voluntárias. Em oposição ao libertarianismo, ninguém deveria ser penalizado(a) por desvantagens atreladas a fatores que se encontram fora do nosso alcance individual.

Entretanto, para críticos e críticas do igualitarismo de fortuna, como Álvaro de Vita, a "ênfase na escolha e na responsabilidade individuais, longe de levar a uma interpretação mais plausível do propósito do igualitarismo", acabou por representar "uma vasta concessão" à crítica anti-igualitária nas sociedades democráticas (Vita, 2011:591) ${ }^{19}$. A concessão a uma retórica libertariana na obra de Dworkin também é enfatizada por Octávio Ferraz, para quem esse recurso poderia ser explicado pelo "contexto político norte-americano [...] no qual o ideal da igualdade não é exatamente capaz de arrebatar corações e mentes" (2007:253). Para esses autores, ao tornar o problema da exploração interpessoal o cerne das preocupações das teorias da justiça, o igualitarismo de fortuna teria fortalecido a retórica política anti-igualitária presente nas democracias contemporâneas, cujo slogan central "livre-iniciativa e responsabilidade individual" tem orientado a luta contra as políticas de bem-estar nas últimas décadas (Mounk, 2015). A ênfase na responsabilidade individual não justifica apenas um ataque direto os fundamentos dos estados de bem-estar social, mas, tal como nos mostra Hacker (2004), costuma orientar também a transformação da própria lógica distributiva dessas políticas, favorecendo regimes distributivos cada vez mais orientados pela condicionalidade de pagamento de benefícios e pela privatização do risco social ${ }^{20}$.

Ainda que concorde com essa crítica, penso que, apenas assinalar uma convergência perversa entre a responsabilidade individual nas teorias da justiça e a retórica da responsabilidade pessoal encampada por movimentos políticos anti-igualitários, não constitui em si mesmo um 
argumento forte contra o igualitarismo de fortuna. Críticas contextualistas não nos ajudam a especificar o que exatamente está errado com a noção de responsabilidade endossada por autores como Dworkin e Arneson. Uma coisa é reconhecer que existe algo de politicamente perverso com teorias da justiça que adotam um modelo de responsabilidade típico de teorias anti-igualitárias, outra, mais exigente, é explicar o que há de errado com essa noção de responsabilidade.

A responsabilidade pessoal certamente ocupa um papel importante em qualquer teoria da justiça - igualitária ou não. Afinal, possuímos boas razões para querer que aquilo que acontece conosco dependa, em algum grau, das nossas escolhas e decisões pessoais. Na verdade, podemos afirmar que existe uma variedade de razões pelas quais a responsabilidade pessoal deve ser valorizada ${ }^{21}$. Em primeiro lugar, a possibilidade de exercer algum grau de controle sobre nossas vidas, isto é, de exercer controle sobre aquilo que nos acomete por meio de escolhas individuais, é uma maneira importante de garantir a proteção dos nossos interesses. Em geral, mesmo que nem sempre, é bom que o que acontece comigo seja resultado das minhas escolhas e do exercício da minha agência individual.

Além disso, escolhas voluntárias possuem um elemento comunicativo implícito: estados de coisas resultantes de escolhas pessoais conferem significado para as ações e para a identidade dos agentes que as realizam. $\mathrm{O}$ fato de alguém poder escolher autonomamente o seu destino torna essa pessoa um agente responsável aos olhos dos demais. Ou seja, para além do valor instrumental, a possibilidade de escolha possui um valor irredutivelmente relacional, quando alguém é reconhecido como uma pessoa responsável por suas próprias decisões. Uma sociedade na qual as instituições sociais não concedam espaço para essas decisões, ou em que certos grupos sociais sejam sistematicamente estigmatizados como aquém dos padrões de responsabilidade socialmente aceitos, será patentemente injusta.

Se valorizamos a autonomia individual - e, como procurei mostrar com base em casos-limite de desrespeito distributivo, uma concepção de igualdade relacional certamente o faz -, então precisamos aceitar que as pessoas devem ser responsabilizadas pelos planos de vida que elas próprias decidem seguir. Como observa Rawls (1999), uma concepção 
democrática de cidadania precisa pressupor que somos "capazes de assumir responsabilidade pelas nossas escolhas", sejam elas boas ou ruins do ponto de vista distributivo (Rawls, 1999:369; Scheffler, 2003).

O que há de errado, então, com a concepção de responsabilidade pessoal presumida pelo igualitarismo de fortuna? Acredito que a introdução de parâmetros distributivos "sensíveis à ambição individual" tenham incorporado ao igualitarismo de fortuna uma noção punitiva de responsabilidade individual. Entendo a noção punitiva de responsabilidade como um caso específico de moralismo institucional, isto é, a crença de que desigualdades podem ser justificadas exclusivamente com base em supostas "falhas morais" daquelas e daqueles penalizados por essas desigualdades (Scanlon, 2018:60)22. Uma noção punitiva de responsabilidade pessoal sustenta não apenas que as pessoas devam ser responsabilizadas por suas escolhas, mas que a melhor forma de garantir isso é atribuir às instituições distributivas a função normativa de vigiar, avaliar e, quando necessário, punir distributivamente o comportamento individual considerado moralmente inaceitável. Um modelo punitivo de instituições distributivas acredita ser conceitualmente possível, e normativamente desejável do ponto de vista das principais instituições sociais, estabelecer um vínculo causal entre alguém ser responsável por um determinado curso de ação, e alguém ser responsável por resultados distributivos coletivos para os quais a sua ação constitui apenas um dos fatores causais relevantes (Mounk, 2015). Caso o agente $S$ aja de forma irresponsável, e caso $S$ esteja em uma posição desfavorável distributivamente, então conclui-se que a situação distributiva desfavorável na qual $S$ se encontra foi causada por sua própria irresponsabilidade. E com base nesse vínculo, $S$ deve ser punido com o auxílio de instituições distributivas. A forma de punição privilegiada nesse caso é a suspensão da validade das reivindicações distributivas de $S$ pelo regime distributivo no qual $S$ é um membro pleno. O raciocínio geral pode ser reformulado do seguinte modo:

p1. As pessoas devem se responsabilizar por suas escolhas individuais;

p2. Cabe às instituições distributivas avaliar e punir as falhas morais;

p3. $S$ tomou decisões erradas, ou irrefletidas, ao longo de sua vida;

C: O regime distributivo do qual $S$ faz parte está autorizado a puni-lo distributivamente. 
Evidentemente, o igualitarismo de fortuna não aceita o argumento de modo irrestrito. Como vimos, suas formulações disputam os padrões de imputação de responsabilidade individual presentes no argumento, isto é, como devemos interpretar o sentido de (p3). Para o igualitarismo de fortuna, as instituições distributivas devem punir apenas escolhas voluntárias, e não as consequências distributivas advindas das circunstâncias não escolhidas de uma pessoa. O ponto importante é aquilo o que o igualitarismo de fortuna não disputa: que o propósito das instituições distributivas em uma sociedade justa é punir comportamentos moralmente objetáveis - isto é, ( $p 2)$. Aceita-se a validade normativa do argumento como um todo, rejeitando apenas o modo como devemos interpretar os casos particulares de irresponsabilidade: uma interpretação cega à arbitrariedade distributiva de talentos e oportunidades sociais. Entretanto, nos casos nos quais é possível rastrear vantagens sociais às decisões voluntárias das pessoas, então regimes distributivos estariam autorizados a identificar e a punir distributivamente as pessoas em nome da justiça.

Com isso o igualitarismo de fortuna acaba por concordar com duas proposições questionáveis próprias da noção punitivista. Em primeiro lugar, o reconhecimento público de que existem dois tipos diferentes de pessoas em desvantagem social: aqueles(as) que realmente merecem, e aqueles(as) que não merecem essa posição; e que com base nesse tipo de juízo avaliativo, a sociedade pode suspender suas obrigações distributivas em relação ao primeiro tipo de pessoa, instaurando uma forma de hierarquia distributiva. Com isso, voltamos às formas de desrespeito distributivo discutidas na na seção intitulada Desrespeito e Distribuição: tanto prejudicados como beneficiados são, de alguma forma, estigmatizados aos olhos dos cidadãos e cidadãs moralmente superiores. Em segundo lugar, e decorrente da primeira proposição, o reconhecimento de que a função primária das instituições distributivas é moralizar o comportamento individual. A noção punitiva de responsabilidade - seja em sua forma geral, seja na versão retificada do igualitarismo de fortuna -, endossa uma visão excessivamente simplista (e a meu ver, normativamente equivocada) das instituições sociais. Arranjos sociais justos possuem uma pluralidade de objetivos normativos distintos, tais como a erradicação da miséria, a promoção de confiança social entre os(as) cidadãos(as), a coletivização de riscos individuais, a estabilização da economia etc. Esses são objetivos tão importantes para a construção de uma sociedade justa como o obje- 
tivo de punir o caronismo. Não é razoável pressupor que a punição distributiva seja o aspecto institucional prioritário de um regime distributivo igualitário.

Uma concepção mais ampla de instituição social precisa estabelecer uma distinção entre escolhas individuais e circunstâncias individualmente arbitrárias (como a riqueza familiar ou a genética) de um lado, e entre escolhas individuais e circunstâncias coletivamente arbitrárias, relacionadas ao funcionamento estrutural das economias de mercado, de outro. A responsabilidade pelos resultados distributivos não depende apenas das decisões individuais às quais nos confrontamos, mas também de decisões coletivas que muitas vezes não se encontram efetivamente abertas à cidadania democrática. Ciclos financeiros e decisões econômicas de longo alcance impactam de modo direto a vida e, consequentemente, a estrutura de escolhas disponíveis para trabalhadores e trabalhadoras. Dada a organização da estrutura produtiva das sociedades capitalistas, trabalhadores individuais possuem pouco ou nenhum controle sobre decisões econômicas fundamentais das sociedades em que vivem, como a qualidade dos empregos ou o nível de investimento. Devemos nos perguntar se a possibilidade de participação sobre a estrutura produtiva da sociedade não seria uma condição crucial para a imputação institucional de responsabilidade econômica (Stanczyk, 2012).

Além disso, instituições distributivas precisam oferecer uma resposta para o que as pessoas devem umas às outras em termos distributivos, mesmo naquelas situações de sofrimento social cujas causas possam ser inteiramente atribuídas ao comportamento de suas vítimas. Nenhum argumento de justiça pode justificar a crueldade estatal contra os irresponsáveis, seja do ponto de vista de princípios morais, seja por conta das consequências dessa omissão para os padrões de solidariedade social. Isso não significa sustentar, por outro lado, que toda política distributiva necessite ser de tipo incondicional, e nem mesmo que políticas distributivas não precisem ser responsivas ao comportamento das pessoas; mas apenas que é razoável esperar certas obrigações distributivas das instituições sociais para com seus membros que independam do caráter de seus beneficiados. O tipo de tolerância institucional que tenho em mente nesse caso não é tão diferente da tolerância em relação aos outros direitos fundamentais da cidadania, como a tolerância para com aqueles que exploram seu direito de voto para demonstrar apoio a candidaturas antidemocráticas, ou à manutenção do devido 
processo legal mesmo em caso de crimes hediondos, nos quais os culpados contavam com esse tipo de reserva. Em todos esses casos, o "caronismo" em questão é algo moralmente reprovável do ponto de vista dos indivíduos. Mas algum grau de caronismo pode ser aceito institucionalmente, tendo em vista outros valores que não a equidade distributiva, tais como o respeito mútuo entre iguais, o valor intrínseco das liberdades fundamentais, e as consequências socialmente benéficas de um sistema estável de seguridade social.

(Recebido para publicação em 12 de abril de 2018)

(Reapresentado em 20 de fevereiro de 2019)

(Aprovado para publicação em 24 de agosto de 2019)

\section{NOTAS}

1. Por teorias igualitárias da justiça entendo concepções de justiça que aceitam a igualdade como um valor moral intrínseco e que esse valor, de algum modo, produz obrigações distributivas para a sociedade. Nesse sentido, nem toda teoria da justiça é igualitária, já que nem toda concepção de justiça aceita o valor intrínseco da igualdade. Como também nem toda forma de igualitarismo é necessariamente uma teoria da justiça, uma vez que existem formas de igualitarismo que não estão fundamentadas em uma concepção de justiça. A não ser que seja indicado, o artigo tem como objeto apenas teorias igualitárias da justiça.

2. Luck egalitarianism no original. Sigo aqui a tradução proposta por Álvaro de Vita (2011). O termo foi cunhado originalmente pela filósofa Elizabeth Anderson (1999).

3. O igualitarismo de fortuna também ocupa lugar de destaque nos manuais de filosofia política de Kymlicka (2006: esp. cap. 3) e Roemer (1998: esp. cap.8).

4. O que estou chamando aqui de visão distributiva da igualdade não deve ser confundida com a famosa crítica de Iris Young (1990) àquilo que a teórica denominou de "paradigma da distribuição" nas teorias da justiça. Young foi uma das primeiras teóricas igualitárias a criticar a ênfase excessiva no aspecto da equidade nas teorias da justiça e, nesse sentido, o artigo partilha das preocupações da autora. Contudo, existem graves problemas de interpretação na formulação de Young, como a tentativa de classificação de teóricos patentemente antidistributivistas, como John Rawls e Stephen Darwall, no paradigma distributivista. Para uma interpretação não distributivista de Rawls, ver Scheffler (2003), Forst (2007) e Petroni (2017a).

5. Seguindo convenção já estabelecida no campo, traduzirei welfare por "bem-estar subjetivo", ou simplesmente "bem-estar", e well-being por "bem-estar objetivo", ou ainda "qualidade de vida". A distinção entre essas duas formas de entender o conceito de welfare é explorada por Sen (1979a, 1979b), e os termos em português podem ser encontrados em Vita (2007). Dois exemplos importantes de métricas mistas são o enfoque das capabilidades de Sen (1979a, 1992), e a "igualdade de oportunidade para vantagens sociais", proposta por Cohen (1993). 


\section{Lucas Petroni}

6. Para uma discussão detalhada sobre como uma teoria do bem (ou do valor) constitui um fator necessário em qualquer teoria normativa, ver Kagan (1998).

7. Sobre a importância do problema da exploração interpessoal na crítica de Nozick, ver Wolff $(1998,2007)$.

8. Para uma apresentação mais recente do argumento, ver Mankiw (2013).

9. Existem discrepâncias importantes no modo como esses fatores arbitrários determinam os índices de mobilidade intergeracional em cada sociedade. Como mostra Miles Corak (2016), por exemplo, o Brasil é o país com a pior correlação entre desigualdade social (Gini) e baixa mobilidade social geracional em um conjunto de 22 países altamente industrializados. Essas diferenças podem ser explicadas, em grande medida, pelo quanto cada sociedade está disposta a reconhecer os elementos arbitrários da distribuição de posições sociais.

10. Dworkin não designa sua teoria como uma teoria sobre a igualdade de oportunidade para recursos sociais. Contudo, como pretendo argumentar a seguir, é plausível reformulá-la desse modo. Agradeço a Thomas Bustamante por chamar minha atenção para esse ponto.

11. Tarambola é um tipo de ave selvagem europeia que bota apenas quatro ovos por ano. Vinhos pré-filoxéricos são vinhos raríssimos produzidos e engarrafados antes da "grande praga da filoxera" que dizimou as vinícolas francesas em meados do século XIX. Os exemplos originais (que remontam a Kenneth Arrow) dizem mais sobre a bem-sucedida inserção da elite acadêmica norte-americana no mundo dos muito ricos do que sobre sua relevância analítica.

12. Notemos também que não se trata de um problema da fraude de preferências (Dworkin, 1981b). No exemplo, Luiz não está mentindo que gostaria de lutar pela causa das tarambolas apenas para ganhar mais recursos do que os outros.

13. Notemos que são os valores de bem-estar atrelados a cada possibilidade de vida, e não as escolhas, que precisam ser as mesmas entre duas pessoas.

14. Segundo Dworkin, seu critério de responsabilização é fundado na "experiência ética cotidiana" das pessoas (Dworkin, 2002). Arneson, por sua vez, tende a caracterizar a própria formação de preferências individuais como uma circunstância arbitrária (Arneson, 2002).

15. Agradeço a Rogério Barbosa por ter me ajudado a compreender esse ponto.

16. Estudos mais detalhados sobre o igualitarismo relacional são encontrados em Wolff (2010), Scheffler (2015) e Petroni (2017a).

17. É interessante notar que Dworkin (cf. 2005:ix e 168-169), em seus trabalhos tardios, tenha enfatizado mais a igual consideração de interesses (equidade), e menos a igualdade de respeito entre as pessoas - como havia enfatizado em seus primeiros trabalhos (Dworkin, 1978) - como sendo a "virtude soberana" da política.

18. Outro exemplo importante de desrespeito distributivo, mas o qual que não tratarei neste artigo, é a equidade distributiva autoritária, isto é, formas não democráticas de distribuição. Dworkin e Arneson, evidentemente, estão longe de endossarem argumentos autoritários. O ponto é que ambos reconhecem que seria possível, em termos 
conceituas, uma sociedade justa, porém autoritária (Dworkin, 1987; Arneson, 2004). Ver Petroni (2017b) para um aprofundamento da relação entre igualitarismo de fortuna, de um lado, e teorias instrumentais da autoridade política, de outro.

19. A convergência entre a predominância política do pensamento de livre-mercado e a predominância teórica do igualitarismo de fortuna na academia norte-americana também é ressaltada por Scheffler (1992) e Mounk (2017b).

20. Agradeço a Gabriel Madeira por ter chamado minha atenção para esse ponto.

21. Para uma análise mais detalhada sobre as diferentes dimensões do valor da escolha, $\mathrm{e}$ seu significado para a responsabilidade pessoal, ver Scanlon (1998).

22. Acredito que uma versão do moralismo institucional esteja presente na crítica de de Vita (2011:593-594) ao que identifica como "duplo padrão" de avaliação presente em certas instituições econômicas: enquanto agentes do mercado financeiro não são moralmente responsáveis por crises econômicas, beneficiários de programas sociais são duramente penalizados por comportamentos "caronistas". 


\section{Lucas Petroni}

\section{REFERÊNCIAS}

ANDERSON, Elizabeth. (1999), "What is the point of equality?". Ethics, v. 109, n. 2, pp. 287-377.

ARNESON, Richard. (1989), "Equality and equal opportunity for Welfare". Philosophical Studies, v. 65, n. 1, pp. 77-93.

. (2002), "Liberalism, distributive subjectivism, and equal opportunity for Welfare", In: M. Clayton; A. Williams (eds.), The ideal of equality. London: Palgrave Macmillan, pp. 182-202.

CAPARRÓS, Martín. (2016), A fome. Rio de Janeiro: Bertrand Brasil.

COHEN, Gerald Allan. (1989), "On the currency of egalitarian justice". Ethics, v. 99, pp. 906-944.

. (1993), "Equality of what? On Welfare, goods and capabilities". In: M. Baum; A. Sen (eds.), The quality of life. Oxford: Oxford Press, pp. 9-29.

. (2011), "Luck and equality". In: M. Otsuka (org.), On the currency of egalitarian justice and other essays in Political Philosophy. New Jersey: Princeton Press, pp. 116-123.

CORAK, Miles. (2016), "Inequality from generation to generation: The United States in comparison". IZA Discussion Paper 7520. Disponível em: http://ftp.iza.org/dp9929. pdf. Acesso em 12 de dezembro de 2018.

DWORKIN, Ronald. (1978), Taking rights seriously. Cambridge, MA.: Harvard University Press.

. (1981a), "What is equality? Part I: equality of Welfare". Philosophy and Public Affairs v. 10, n. 3, pp. $185-246$.

. (1981b), "What is equality? Part II: equality of resources". Philosophy and Public Affairs, v. 10, n. 4, pp. 283-354.

. (1987), "What is equality? Part 4: political equality". University of San Diego Law Review, v. 22 (Marshall P. Madison Lecture), pp. 1-30.

. (2005), A Virtude soberana: a teoria e prática da igualdade. São Paulo: Martins Fontes.

FERRAZ, Octávio Luiz Motta. (2007), "Justiça distributiva para formigas e cigarras". Revista Novos Estudos Cebrap, n. 77, pp. 243-253. Disponível em: http://www.scielo.br/scielo. php?script=sci_arttext\&pid=S0101-33002007000100013. Acesso em 21 de dezembro de 2017.

FORST, Rainer. (2007), “Radical Justice: On Iris Marion Young's critique of the 'distributive paradigm'". Constellations, v. 14, n. 2, pp. 260-265.

HACKER, Jacob. (2004), "Privatizing risk without privatizing the Welfare State: the hidden policy of social policy retrenchment in the United States". The American Political Science Review, v. 98, n. 2, pp. 243-260.

HAYEK, Friedrich A. (1960), The constitution of liberty. Chicago: The University of Chicago Press.

KAGAN, Shelly. (1998), Normative ethics. Boulder, Colorado: Westview Press. 
KYMLICKA, Will. (2006), Filosofia política contemporânea. São Paulo: Martins Fontes.

MANKIWN, Gregory N. (2013), "Defending the One Percent". Journal of Economic Perspectives v. 27 , n. 3, pp. 21-34.

MOUNK, Yascha. (2015), The age of responsibility: on the role of choice, luck and personal responsibility in contemporary politics and philosophy. Tese (Doutorado). Harvard University, Graduate School of Arts \& Sciences. Disponível em: https: / dash.harvard. edu/bitstream/handle/1/14226053/MOUNK-DISSERTATION-2015.pdf. Acesso em 11 de fevereiro de 2018 .

. (2017), "Responsibility redefined". Democracy: A Journal of Ideas, n. 43. Disponível em: https://democracyjournal.org/magazine/43/responsibility-redefined/. Acesso em 11 de fevereiro de 2018.

NOZICK, Robert. (1974), Anarchy, state and utopia. New York: Basic Books.

PETRONI, Lucas. (2017a), A moralidade da igualdade. Tese (Doutorado em Ciência Política), Universidade de São Paulo, São Paulo. Disponível em: http:/ / www.teses.usp.br/teses / disponiveis /8/8131/tde-08122017-160256/pt-br.php. Acesso em 21 de dezembro de 2017.

. (2017b), "Igualdade e respeito deliberativo". In: D. Werle et al. (orgs.), Justiça, teoria crítica e democracia. Florianópolis: NEFIPOnline. Disponível em: http:/ / www.nefipo. ufsc.br/files/2017/10/Justi\%C3\%A7a-Teoria-Cr\%C3\%ADtica-e-Democracia.pdf. Acesso em 21 de dezembro de 2017.

RAWLS, John. (1997), Uma teoria da justiça. Trad. Jussara Simões. São Paulo: Martins Fontes. . (1999), "Social unity and primary goods". In: S. Freeman (ed.), John Rawls: Collected Papers. Cambridge, MA.: Harvard University Press, pp. 359-387.

. (2011), O liberalismo político. Trad. Álvaro de Vita. São Paulo: Martins Fontes.

ROEMER, John. (1998), Theories of distributive justice. Cambridge, MA.: Harvard University Press.

SCANLON, Thomas. (1998), What we owe to each other. Cambridge, MA.: Harvard University Press.

. (2003), "What is egalitarianism?". Philosophy E Public Affairs, v. 31, n. 1, pp. 5-39.

. (2015), "The practice of equality". In: C. Fouire; F. Schuppert; I. Walliman-Helmer (eds.), Social equality: on what it means to be equal. Oxford: Oxford Press, pp. 21-44.

(2018), Why does inequality matter? Oxford: Oxford University Press.

SEN, Amartya. (1979a), "Equality of what?" The Tanner Lectures in Human Values (Delivered at Stanford University. Disponível em: https:/ / tannerlectures.utah.edu/_documents/ato-z/s/sen80.pdf. Acesso em 19 de dezembro de 2017.

(1979b), "Utilitarianism and welfarism". The journal of Philosophy, v. 76, n. 9, pp. 463-489.

(1992), Inequality reexamined. Cambridge: Harvard University Press.

STANCZYK, Lucas. (2012), "Productive justice". Philosophy and Public Affairs v. 40, n. 2, pp. 144-164. 


\section{Lucas Petroni}

VITA, Álvaro de. (2007), A justiça igualitária e seus críticos. São Paulo: Martins Fontes. . (2011), "Liberalismo, justiça social e responsabilidade individual". DADOS - Revista de Ciências Sociais, v. 54, n. 4, pp. 569-608. Disponível em: http:/ /www.scielo.br/scielo. php?script=sci_arttext\&pid=S0011-52582011000400003. Acesso em 21 de dezembro de 2017.

WOLFF, Jonathan. (1998), "Fairness, respect and the egalitarian ethos". Philosophy and Public Affairs, v. 27, n. 2, pp. 97-122.

. (2007), "Equality: the recent history of an idea". Journal of Moral Philosophy, v. 4, n. 1, pp. 125-136. Disponível em: http://booksandjournals.brillonline.com/content/ journals/10.1177/1740468107077389. Acesso em 21 de dezembro de 2017.

. (2010), "Fairness, respect and the egalitarian ethos revisited". The Journal of Ethics, v. 14 n. 3/4, pp. 335-350.

YOUNG, Iris Marion. (1990), Justice and the politics of difference. New Jersey: Princeton University Press. 


\section{RESUMO \\ O Que Há de Errado com o Igualitarismo de Fortuna?}

O objetivo geral do artigo é argumentar por que o igualitarismo de fortuna defendido por autores como Ronald Dworkin, Richard Arneson e G. A. Cohen é uma forma equivocada de conceber o ideal igualitário. Para isso, o artigo propõe uma distinção entre dois tipos de críticas ao igualitarismo de fortuna: uma interna e de natureza conceitual, centrada na linha de corte entre escolhas voluntárias e circunstâncias não voluntárias; e uma crítica igualitária, que tem como objeto o fundamento normativo das teorias igualitárias. $\mathrm{O}$ artigo argumenta que a crítica igualitária (mas não necessariamente a interna) tem como consequência uma mudança de prioridades da agenda de pesquisa igualitária. Em oposição ao problema da exploração interpessoal, concepções relacionais de igualdade priorizam a pergunta sobre como devemos conceber os sujeitos da justiça, isto é, como devemos conceber nossas relações normativas enquanto reciprocamente responsáveis pela criação de uma sociedade justa. Finalmente, o artigo toma o papel da responsabilidade pessoal nas teorias da justiça como um caso ilustrativo da diferença entre a visão distributiva e a visão relacional do valor moral da igualdade.

Palavras-chave: teorias da justiça; igualdade; igualitarismo de fortuna; responsabilidade; igualdade de oportunidade

\section{ABSTRACT \\ What's Wrong with Equality of Fortune?}

The general purpose of this article is to argue why the "luck egalitarianism" or "equality of fortune", advocated by authors such as Ronald Dworkin, Richard Arneson, and G. A. Cohen, is a mistaken way of conceiving the egalitarian ideal. To this end, the article proposes a distinction between two types of criticism of equality of fortune: one internal and conceptual, centered on the cutting line between voluntary choices and non-voluntary circumstances; and an egalitarian critique, whose object is the normative foundation of egalitarian theories. The paper argues that egalitarian (but not necessarily internal) criticism results in a shift in priorities from the egalitarian research agenda. In opposition to the problem of interpersonal exploitation, relational conceptions of equality prioritize the question of how we should conceive the subjects of justice, that is, how we should conceive our normative relations as reciprocally responsible for the creation of a just society. Finally, the article takes the role of personal responsibility in theories of justice as an illustrative case of the difference between the distributive view and the relational view of the moral value of equality. 


\section{Lucas Petroni}

Keywords: theories of justice; equality; equality of fortune; accountability; equal opportunity

\section{RÉSUMÉ \\ Qu'est-ce qui ne va pas avec "Luck Egalitarianism"?}

L'objectif général de l'article est de montrer pourquoi l'égalitarisme de la fortune prôné par des auteurs tels que Ronald Dworkin, Richard Arneson et G. A. Cohen est une manière erronée de concevoir l'idéal égalitaire. À cette fin, l'article propose une distinction entre deux types de critiques de l'égalitarisme de la fortune: une de nature interne et conceptuelle, centrée sur la ligne de démarcation entre les choix volontaires et des circonstances non volontaires; et une critique égalitaire, dont l'objet est le fondement normatif des théories égalitaires. L'article discute que la critique égalitaire (mais pas nécessairement interne) entraîne un changement de priorités par rapport au programme de recherche égalitaire. En opposition au problème de l'exploitation interpersonnelle, les conceptions relationnelles de l'égalité privilégient la question de savoir comment concevoir les sujets de justice, c'est-à-dire comment concevoir nos relations normatives comme réciproquement responsables de la création d'une société juste. Enfin, l'article prend le rôle de la responsabilité personnelle dans les théories de la justice comme un exemple illustratif de la différence entre la vision distributive et la vision relationnelle de la valeur morale de l'égalité.

Mots-clés: théories de la justice; de l'égalité; de l'égalité des fortunes; de la responsabilité; de l'égalité des chances

\section{RESUMEN \\ ¿Qué hay de equivocado con el Igualitarismo de la Fortuna?}

El objetivo general del artículo es argumentar por qué el igualitarismo de la fortuna defendido por autores como Ronald Dworkin, Richard Arneson y G. A. Cohen es una forma equivocada de concebir el ideal igualitario. Para eso, el artículo propone una distinción entre dos tipos de críticas al igualitarismo de la fortuna: una interna y de naturaleza conceptual, centrada en la línea de corte entre elecciones voluntarias y circunstancias no voluntarias; y una crítica igualitaria, que tiene como objeto el fundamento normativo de las teorías igualitarias. El artículo argumenta que la crítica igualitaria (pero no necesariamente la interna) tiene como consecuencia un cambio de prioridades de la agenda de investigación igualitaria. En oposición al problema de la exploración interpersonal, concepciones relacionales de igualdad priorizan la pregunta sobre como debemos concebir los sujetos de la justicia, es decir, como debemos concebir nuestras relaciones normativas, en tanto 
que son recíprocamente responsables por la creación de una sociedad justa. Finalmente, el artículo toma el papel de la responsabilidad personal en las teorías de la justicia como un caso ilustrativo de la diferencia entre la visión distributiva y la visión relacional del valor moral de la igualdad.

Palabras clave: teorías de la justicia; igualdad; igualitarismo de la fortuna; responsabilidad; igualdad de oportunidad 